

\title{
Sensitive Determination of Acetaminophen in the Presence of Dopamine and Pyridoxine Facilitated by their Extent of Interaction with Single-walled Carbon Nanotubes
}

Mamta Yadav, Vellaichamy Ganesan, Biswajit Maiti, Rupali Gupta, Piyush Kumar Sonkar, Dharmendra Kumar Yadav, Alain Walcarius

\section{To cite this version:}

Mamta Yadav, Vellaichamy Ganesan, Biswajit Maiti, Rupali Gupta, Piyush Kumar Sonkar, et al.. Sensitive Determination of Acetaminophen in the Presence of Dopamine and Pyridoxine Facilitated by their Extent of Interaction with Single-walled Carbon Nanotubes. Electroanalysis, 2019, 10.1002/elan.201900178 . hal-02324690

\author{
HAL Id: hal-02324690 \\ https://hal.science/hal-02324690
}

Submitted on 27 Nov 2020

HAL is a multi-disciplinary open access archive for the deposit and dissemination of scientific research documents, whether they are published or not. The documents may come from teaching and research institutions in France or abroad, or from public or private research centers.
L'archive ouverte pluridisciplinaire HAL, est destinée au dépôt et à la diffusion de documents scientifiques de niveau recherche, publiés ou non, émanant des établissements d'enseignement et de recherche français ou étrangers, des laboratoires publics ou privés. 
Sensitive determination of acetaminophen in the presence of dopamine and pyridoxine facilitated by their extent of interaction with single walled carbon nanotubes

Mamta Yadav ${ }^{[a]}$, Vellaichamy Ganesan ${ }^{[a]}$, Biswajit Maiti*[a], Rupali Gupta ${ }^{[a]}$, Piyush Kumar Sonkar ${ }^{[a]}$, Dharmendra Kumar Yadav ${ }^{[a]}$, Alain Walcarius ${ }^{*[b]}$

${ }^{[\mathrm{a}]}$ Department of Chemistry, Institute of Science, Banaras Hindu University, Varanasi221005, UP, India

Telephone: +91-542-2307321, Fax:+91-542-2368127 Email: velganesh@yahoo.com (VG) and velgan@bhu.ac.in (VG), bmaiti@bhu.ac.in (BM)

${ }^{[b]}$ Laboratoire de Chimie Physique et Microbiologie pour les Matériaux et l'Environnement (LCPME), UMR 7564 CNRS - Université de Lorraine, 405 rue de Vandoeuvre, 54600 Villers-les-Nancy, France.

Tél:+33(0)372747375 Fax: +33(0)383275444 Email: alain.walcarius@univ-lorraine.fr (AW) 


\section{Abstract}

Single walled carbon nanotubes (SWCNTs) were immobilized on glassy carbon (GC) electrode by drop casting The resulting modified electrode (represented as GC/SWCNTs) efficiently oxidizes acetaminophen (AC), dopamine (DA) and pyridoxine (PY) by decreasing the respective oxidation potentials and increasing peak currents in comparison to bare GC electrode. The extent of lowering overpotentials is in the order of $\mathrm{AC}>\mathrm{PY}>\mathrm{DA}$, in agreement with the order of decrease in the HOMO-LUMO energy gap $(\Delta E)$ of these analytes, as determined from Density Functional Theory (DFT) calculations. DFT calculations further reveal that due to the adsorption of the analytes on the $\operatorname{SWCNT}(10,10)$ there is a negative charge density transfer (higher probability of electron transfer, lower $\Delta E$ value) to the frontier molecular orbitals of the analytes, which eases their oxidation. Since AC, DA and PY oxidize distinctly at distinct potential values, the present SWCNTs modified electrodes could be used to simultaneously determine them. Cyclic voltammetry, differential pulse voltammetry and amperometry techniques are utilized to understand the electrochemical characteristics of the analytes (AC, DA and PY) and subsequent sensing of them at the GC/SWCNTs electrode. The electrode is then applied to the determination of Ac as a case study. Sensitivity, detection limit and linear calibration range for the AC are found to be $7.9 \mu \mathrm{A} \mu \mathrm{M}^{-1} \mathrm{~cm}^{-2}, 1.1 \mu \mathrm{M}$ and $2.0-100.0 \mu \mathrm{M}$, respectively.

Keywords: Acetaminophen oxidation - Dopamine oxidation • Pyridoxine oxidation • Electrocatalysis $\bullet$ Single walled carbon nanotubes $\bullet$ DFT calculations 


\section{Introduction}

Acetaminophen (AC) is a common antipyretic and analgesic drug which is mainly employed to decrease fever and to relieve pains associated with muscular, arthritis, post-operation, toothache, headache, backache, etc. [1-4]. In case of contraindication to aspirin, for instance, $\mathrm{AC}$ is considered as the best alternative for patients. Small dosages of AC generally do not cause any harmful side-effects; however over-dosage may lead to kidney and liver damages [3]. The long term use of AC may have fatal neurotoxic and hepatotoxic effects [2]. Thus, it is essential to get an accurate, easy to handle, fast and sensitive analytical technique for the frequent determination of AC [2]. Dopamine (DA) is a neurotransmitter which exists in central and peripheral nervous systems of mammals $[1,5,6]$. Low concentration levels of DA in human body generally lead to Parkinson's disease [1]. DA is supplied as medication to such patients, however excess dosage may cause increased heart beat and blood pressure because of its effect on sympathetic nervous system [1]. Therefore, regular monitoring of DA levels in human body is necessary [7]. Pyridoxine (PY), otherwise known as vitamin $\mathrm{B}_{6}$ is a water soluble vitamin which plays significant role in body cells maintenance and in amino acids metabolism [8-10]. Three forms of PY are available which are known as, pyridoxal, pyridoxol and pyridoxamine [8-10]. PY is also necessary for physical and mental growth of the individual [11]. It is reported that vitamin $\mathrm{B}_{6}$ imposes major effects on gene modulation, sexual behaviour, and immune modulation in HIV-1 infection [9]. Insufficient concentration level of PY in body leads to illness and various sicknesses such as hypertension, cardiovascular problems, hyperlipidemia, obesity and anaemia $[8,10,11]$. Hence, accurate PY determination is essential in human health diagnostics. Due to their complementary features/properties (nutrient, biologically important molecule, or drug), these compounds have been used as representative analytes in the context of the present study. 
Variety of methods which include HPLC, flow injection analysis, liquid chromatography, etc. were reported for the sensing of the above analytes [1-18]. However, they can suffer from low selectivity, poor detection limit, tedious sample preparation procedure, high cost, etc. Electrochemical methods can offer several advantages like low detection limit, high high sensitivity and good selectivity if the electrode surface is modified with suitable catalytic materials. The electrode modification requires only small amount of additional materials and the resulting electrodes can decrease the electrode fouling effects and detect the target analytes at low overpotentials [19]. Recently, carbon based nanomaterials enticed the electrochemists extensively due to efficient promotion of electron transfer events on their surfaces [20-28]. Carbon nanotubes (CNTs) are attractive nanomaterials which possess several interesting properties from the electroanalytical point of view, including high conductivity, durable mechanical stability and high surface area [20-24]. These unique properties of CNTs are exploited in electrochemical science and technology to immobilize electrocatalysts and to increase the electrical communication within the immobilized molecules [20-24]. For example, increased oxidation currents are reported for cysteine, glucose, DA, epinephrine and ascorbic acid detection thanks to presence of CNTs on electrodes $[22,24,29]$. These huge improvements facilitated by the CNTs may be attributed to specific interactions of CNTs with the target analytes through $\pi-\pi$ interaction and/or Van der Waals forces, or the presence of edge-plane-like defect sites [30-34]. In addition to these interactions, depending upon the functional groups of the analytes (phenolic, hydroxyl, amine and $-\mathrm{NHCOCH}_{3}$ groups) they may have specific interactions to CNTs. Though numerous CNTs based composite materials are described to be beneficial in electrochemical sensing [20-24, 30-33], it should be noted here that the influence of CNTs alone on the electrochemical sensing process is not so studied in detail so far [1,17,29,35-38]. Hence, in 
this study a simple, sensitive and cost effective electrochemical route for the efficient quantification of AC, DA and PY based on single walled CNTs immobilized glassy carbon electrodes is reported. The originality not only relies on the simultaneous analysis of these three analytes, but also on the use of additional theoretical calculations carried out to confirm the results obtained from electrochemical studies, which remains underexplored to date [3941]. This work is expected to strengthen the existing knowledge on the adaptability of CNTs for the electroanalysis of biologically-relevant molecules.

\section{Experimental}

\subsection{Reagents and chemicals}

Single walled carbon nanotubes (SWCNTs), AC and DA were obtained from Sigma-Aldrich. Phosphate buffer of $\mathrm{pH} 7.0(0.1 \mathrm{M})$ was prepared by mixing appropriate amounts of $\mathrm{K}_{2} \mathrm{HPO}_{4}$ and $\mathrm{KH}_{2} \mathrm{PO}_{4}$ (Qualigens, Mumbai, India) stock solutions. N, N-dimethyl formamide (DMF) and PY were purchased from S.D. Fine Chemicals, India. All chemicals were used as received and all solutions were prepared from triple distilled water.

\subsection{Instrumental details}

All electrochemical experiments have been performed using the $\mathrm{CH}$ Instruments' electrochemical workstation (model: CHI-660C), along with a three electrodes-single compartment cell system. Bare glassy carbon (GC) electrode or modified GC was used as working electrodes. A Pt wire and $\mathrm{KCl}$ saturated calomel electrode were employed as counter and reference electrodes, respectively. Electrochemical studies were carried out at room temperature in $0.1 \mathrm{M}$ phosphate buffer ( $\mathrm{pH}$ 7.0) unless otherwise mentioned. Prior to each electrochemical analysis, nitrogen gas was purged into the supporting electrolyte solution for $20 \mathrm{~min}$ to remove the dissolved oxygen. 


\subsection{Modification of working electrode}

GC electrode was cleaned by rubbing it over the Buehler-felt pad with alumina slurry followed by ultra-sonication in triple distilled water. Colloid of SWCNTs was prepared in DMF (1.0\%) by ultra-sonicating the mixture for $20 \mathrm{~min}$. A $10 \mu \mathrm{L}$ of the colloid was dropped over the clean GC electrode and dried for $12 \mathrm{~h}$ (represented as GC/SWCNTs).

\subsection{Theoretical calculations}

To understand the interaction between the SWCNTs and AC, DA and PY at the molecular level and hence to find out the change in oxidation properties of these molecules after adsorption onto SWCNTs, quantum chemical calculations were done based on the density functional theory (DFT, M06-2X/6-31G(d,p)). Gaussian 09 suits of program were used for the calculations [42]. For the SWCNT model, zigzag $(10,10)$ nanotube was used (represented as SWCNT(10,10)). It contains five aromatic-ring chains and length of this SWCNT model can hold the target analytes (AC, DA and PY) well within the SWCNT structure.

\section{Results and discussion}

\subsection{Cyclic voltammetry characterization of AC, DA, and PY at GC and GC/SWCNTs electrodes}

Fig. 1 shows typical cyclic voltammograms (CV) recorded at a scan rate of $25 \mathrm{mV} \mathrm{s}^{-1}$ using GC and GC/SWCNTs electrodes for the oxidation of AC, DA, and PY in $0.1 \mathrm{M} \mathrm{pH} 7.0$ phosphate buffer. CV responses clearly manifest the fact that both GC and GC/SWCNTs provide a potential window wide enough to examine the electrochemical behaviour of these 
target analytes. The $\mathrm{CV}$ responses of $0.2 \mathrm{mM}$ AC at bare GC and GC/SWCNTs electrodes are shown in Fig. 1a, corresponding to a well-established redox process (Eq. 1) [43]. Compared to the quasi-reversible signal for AC on bare GC electrode (with an anodic peak occurring at $510 \mathrm{mV}$ ), the use of GC/SWCNTs electrode results in lower overpotential for AC oxidation (anodic peak potential at $386 \mathrm{mV}$ ) and currents larger by more than one order of magnitude. The decrease in oxidation potential $(124 \mathrm{mV})$ and huge increase in peak current (34 times) at GC/SWCNTs electrode indicate the efficient electrocatalytic effect exhibited by SWCNTs towards the oxidation of AC. During the reverse scan, it exhibits a reduction peak at $330 \mathrm{mV}$ which may be ascribed as per the Eq. 1 .

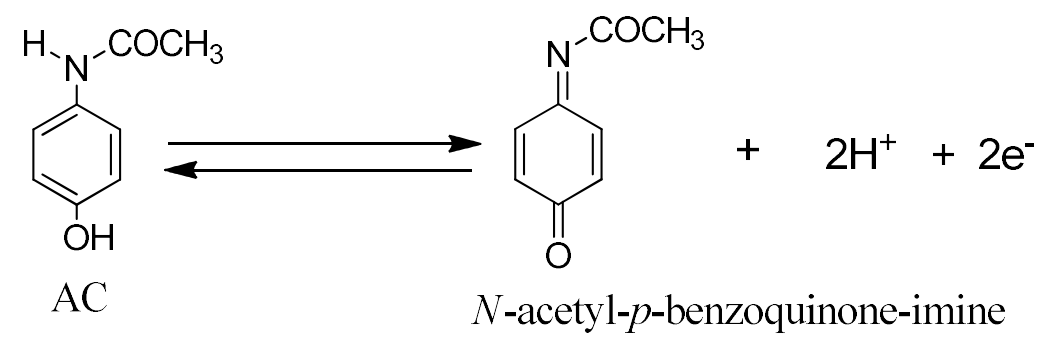

DA exhibits an oxidation peak around $245 \mathrm{mV}$ at bare GC, while it shows a decreased oxidation peak potential $(190 \mathrm{mV})$ with higher current at GC/SWCNTs (Fig. 1b), due to the oxidation of DA according to the process reminded at Eq. 2 [44]. The noticeable shift in the oxidation peak potential $(55 \mathrm{mV})$ towards the less positive values with higher current $(17$ times) at GC/SWCNTs indicate confirm the electrocatalytic properties of SWCNTs towards DA oxidation [35]. The oxidized DA is reduced back in the reverse scan at $160 \mathrm{mV}$. The anodic to cathodic peak-to-peak separation of $30 \mathrm{mV}$ is in good agreement with a fast electron transfer process.

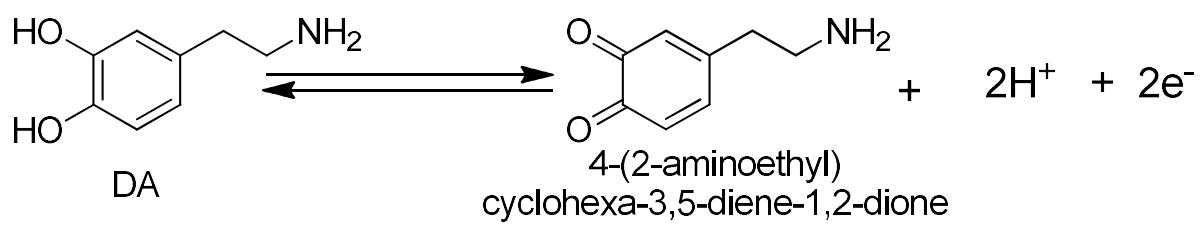



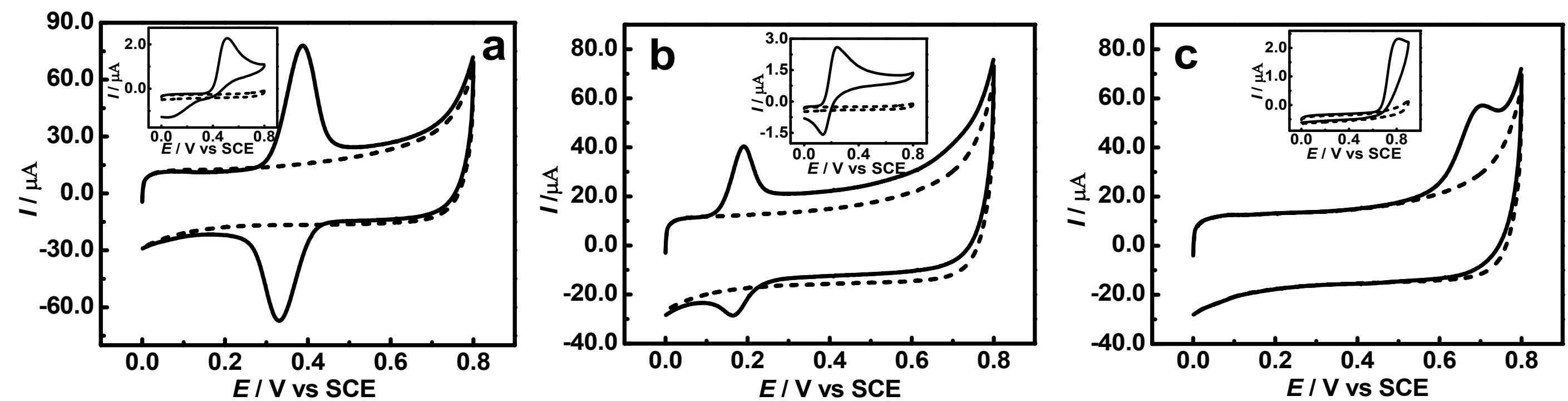

Fig. 1. CV curves recorded at GC/SWCNTs electrode in absence (dashed line) and presence (solid line) of 0.2 mM AC (a), $0.2 \mathrm{mM} \mathrm{DA}(\mathrm{b})$ and $0.2 \mathrm{mM}$ PY (c) in $0.1 \mathrm{M} \mathrm{pH} 7.0$ phosphate buffer (scan rate: $25 \mathrm{mVs}^{-1}$ ). Inset shows cyclic voltammograms recorded at bare GC electrode under the similar conditions. 
Similarly, PY is oxidized at $812 \mathrm{mV}$ with low current at bare GC, while easier oxidation takes place at GC/SWCNTs (peak potential around $700 \mathrm{mV}$, see Fig. 1c). The observed decrease in the oxidation peak potential (by $112 \mathrm{mV}$ ) with concomitant current increase (25 times) when passing from bare $\mathrm{GC}$ to the GC/SWCNTs demonstrate the catalytic properties of SWCNTs towards the oxidation of PY, although the overall process remains non reversible even at the GC/SWCNTs electrode. The probable reaction is shown in the Eq. $3[8,45]$.

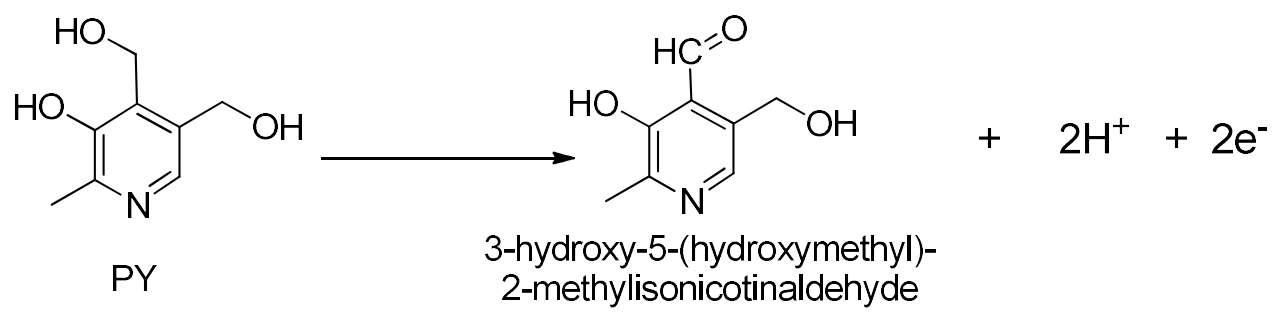

From the above results, it is clear that all three analytes are oxidized electrocatalytically at the GC/SWCNTs electrode (based on the decrease in the oxidation overpotentials, and also the increase in oxidation currents but this latter has to be nuanced by the larger electroactive surface area provided by SWCNTs). The extent of decrease in oxidation peak potentials is found to be in the order of $\mathrm{AC}>\mathrm{PY}>\mathrm{DA}(130,112$, and $55 \mathrm{mV}$ for $\mathrm{AC}, \mathrm{PY}$ and $\mathrm{DA}$, respectively).

DFT calculations are carried out to verify the conclusions drawn from CV experiments. Isosurfaces for the individual $\mathrm{AC}, \mathrm{DA}$ and $\mathrm{PY}$ molecules as well as for their adsorption complexes with SWCNT(10,10) are shown (Fig. 2) to compare the changes in their electronic structure upon adsorption. From Fig. 2 one can see that the negative potential (shown in red) increases after adsorption of analyte molecules on the outer surface of SWCNT(10,10) when compared to the individual molecules, indicating that the oxidation potential decreases for all 
the three compounds after adsorption, which is consistent with the above electrochemical observations. The extent of decrease in the oxidation potential might be correlated to the HOMO-LUMO energy gap ( $\left.\Delta E=E_{\mathrm{LUMO}}-E_{\mathrm{HOMO}}\right)$ of the individual molecules. The lower is the $\Delta E$ value, stronger is the interaction with the $\operatorname{SWCNT}(10,10)$ due to the more facile electron transfer from the SWCNT $(10,10)$ surface to the LUMO of the individual molecules. As a matter of fact that the removal of electron from the HOMO of the corresponding molecule (i.e., oxidation) will be easier and hence greater is the extent of the decrease in potential. The computed $\Delta E$ values for AC, PY and DA are $177.6,180.8$ and $185.1 \mathrm{kcal} / \mathrm{mol}$, respectively. Therefore, the extent of decrease in oxidation potential would be in the following order: AC > PY > DA, which corroborates the experimental results. 


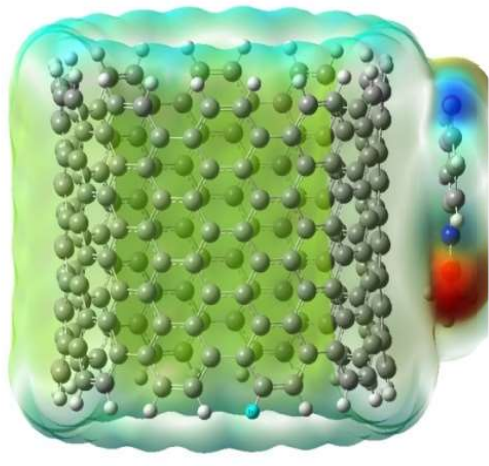

AC-SWCNT $(10,10)$

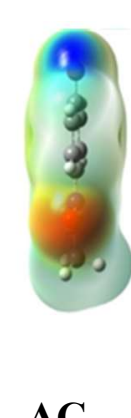

AC

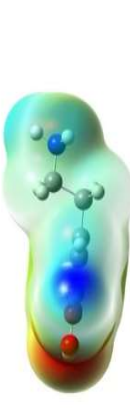

DA

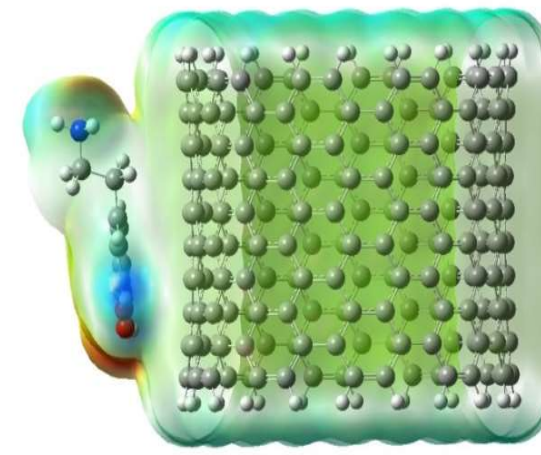

DA-SWCNT(10,10)

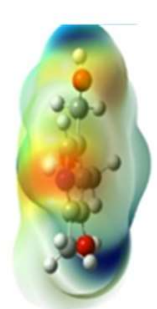

PY

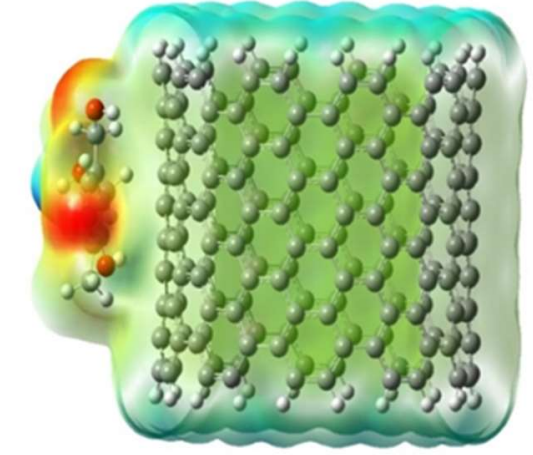

PY-SWCNT(10,10)

Fig. 2. Isosurfaces for molecular electrostatic potential of individual analytes and their adsorption complexes with SWCNT(10,10). The negative and positive potentials are shown in red and blue colour, respectively. 

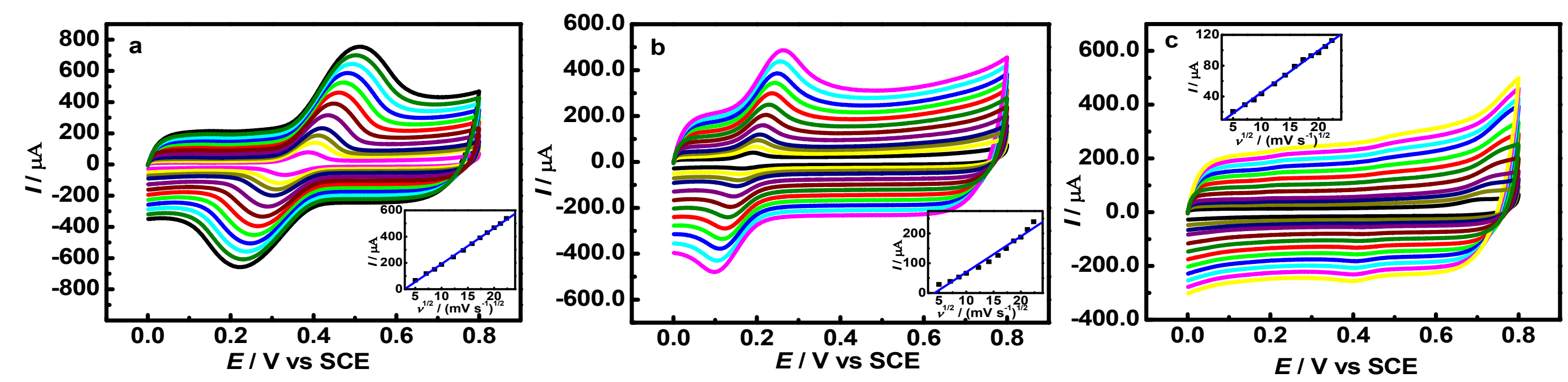

Fig. 3. $\mathrm{CV}$ curves of $0.2 \mathrm{mM} \mathrm{AC} \mathrm{(a),} 0.2 \mathrm{mM}$ DA (b) and $0.2 \mathrm{mM}$ PY (c) in $0.1 \mathrm{M}$ pH 7.0 phosphate buffer at GC/SWCNTs electrode with different scan rates. Inset shows the linear relationship between the current and square root of the scan rate. 
Fig. 3 shows $\mathrm{CV}$ response for the oxidation of $\mathrm{AC}, \mathrm{DA}$, and $\mathrm{PY}$ at various potential scan rates, as recorded using the GC/SWCNTs electrode. On increasing the scan rate, an increase in the currents is observed (Fig. 3a-3c), with anodic peak currents being directly proportional to the square root of the scan rate (see insets in Fig. 3a-3c), indicating redox processes controlled by diffusion.

Fig. 4 shows the simultaneous oxidation of AC, DA, and PY at bare GC and GC/SWCNTs electrodes. Three distinct peaks for the oxidation of AC, DA, and PY are obtained at the GC/SWCNTs electrode at the oxidation peak potentials 374,195 and $705 \mathrm{mV}$, respectively. These oxidation peak potentials are matching well with the oxidation peak potentials of individual oxidation of the respective analytes. These observations specify that the efficiency of individual analyte oxidation process is not affected by the presence of other components in the system. Since the peak potential difference between the individual anodic peaks are distinctly high (c.a., $180 \mathrm{mV}$ between $\mathrm{DA}$ and $\mathrm{AC}$ and $330 \mathrm{mV}$ between $\mathrm{AC}$ and PY), it is expected to carry out the simultaneous determination of these analytes in mixture. At bare GC electrode, for a mixture of AC, DA and PY, only two oxidation peaks are observed with quite low currents and overlapping considerably (see inset on Fig. 4). Thus, bare GC electrode is not appropriate for the quantification of the analytes in presence of each other. 


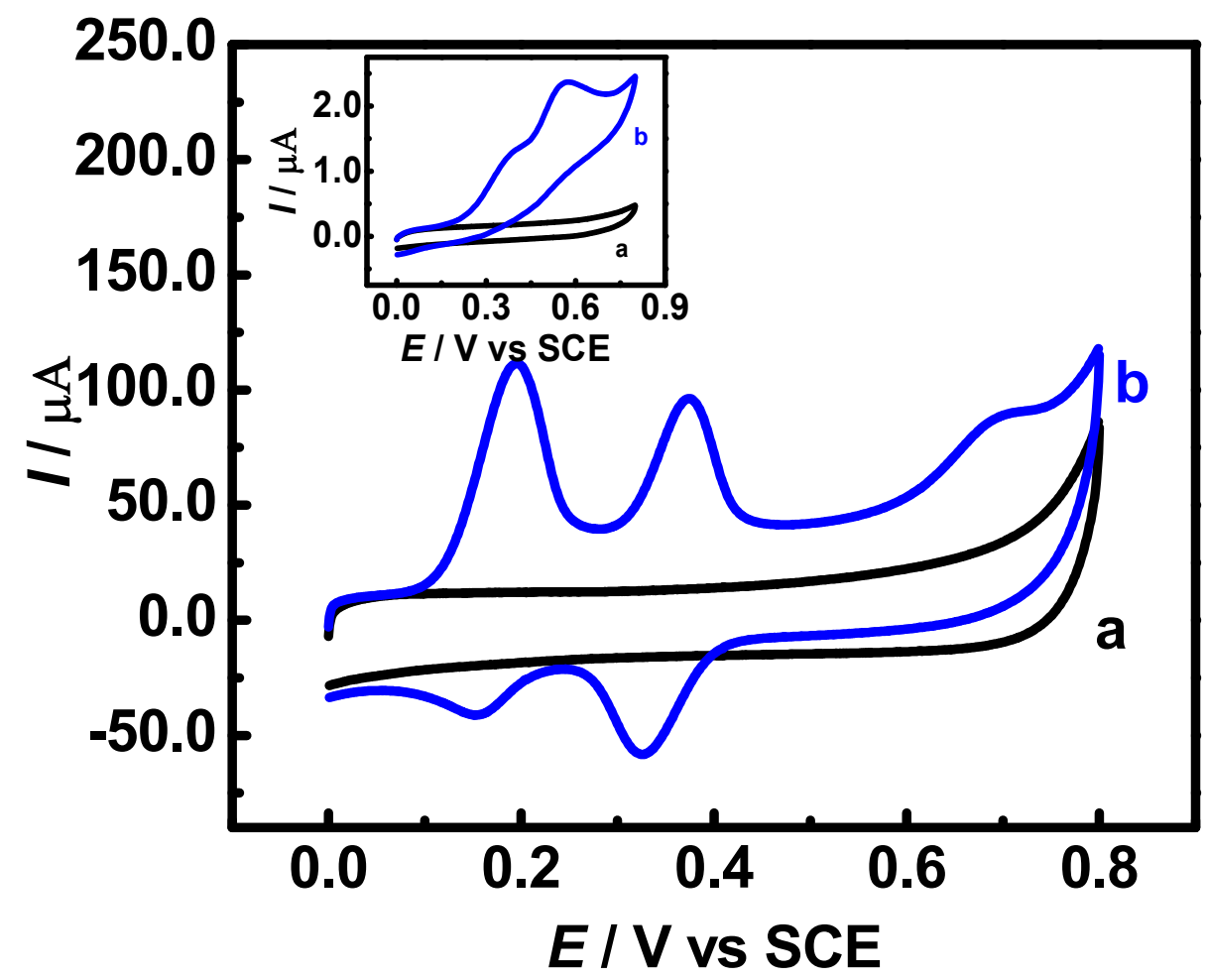

Fig. 4. CV responses recorded at GC/SWCNTs electrode in absence (a) and presence (b) of a mixture of analytes containing $\mathrm{AC}, \mathrm{DA}$, and $\mathrm{PY}$ (each $0.2 \mathrm{mM}$ ) in $0.1 \mathrm{M} \mathrm{pH} 7.0$ phosphate buffer (scan rate: $25 \mathrm{mVs}^{-1}$ ). Inset shows the same at bare GC electrode.

\subsection{Electroanalytical determination of AC, DA and PY}

Among the various electrochemical methods, differential pulse voltammetry (DPV) is one of the most sensitive analytical techniques which can be used for the selective electroanalysis of various analytes at trace levels. Typical DPV responses obtained for increasing concentrations of the analytes studied here (AC, DA and PY) at the GC/SWCNTs are shown in Fig. 5. The results are shown respectively for $\mathrm{AC}$ (in the 2.0 to $100 \mu \mathrm{M}$ concentration range, see Fig. 5a), DA (5-750 $\mu \mathrm{M}$ range, see Fig. 5b), and PY (50-1000 $\mu \mathrm{M}$ range, see Fig. 5c). In all cases, when the analyte concentration is incrementally increased there is a regular enhancement in the oxidation peak currents. One can also see from the corresponding calibration plots (insets on Fig. 5) that variations are linear for all the analytes (with an $r$ values of more than 0.99 ). These plots enable estimating sensitivity values of $7.86 \mu \mathrm{A} \mu \mathrm{M}^{-1}$ $\mathrm{cm}^{-2}, 3.66 \mu \mathrm{A} \mu \mathrm{M}^{-1} \mathrm{~cm}^{-2}$ and $0.31 \mu \mathrm{A} \mu \mathrm{M}^{-1} \mathrm{~cm}^{-2}$, respectively for AC, DA and PY. 

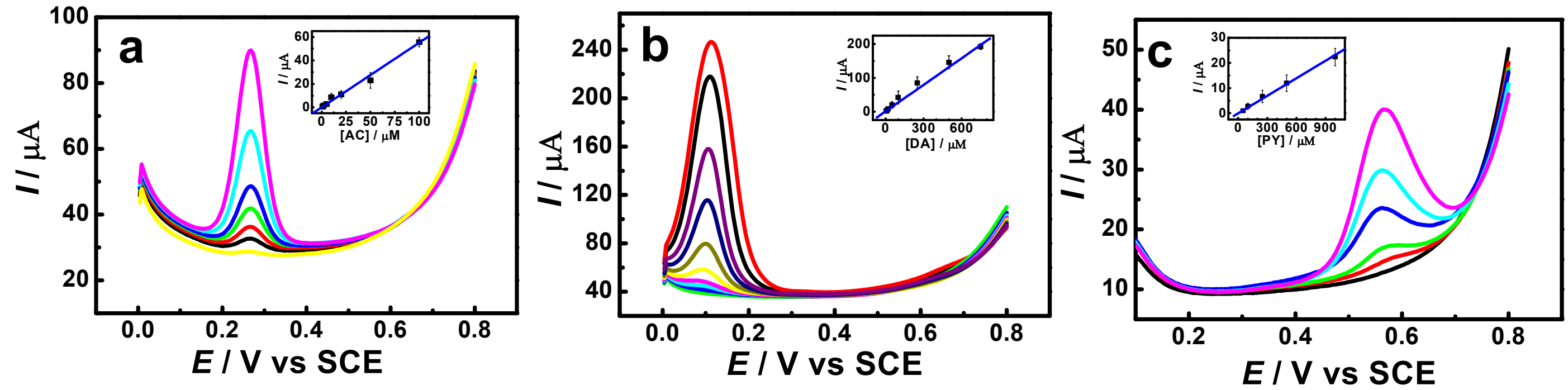

Fig. 5. DPV curves at GC/SWCNTs for various concentrations of $\mathrm{AC}(\mathrm{a}, 2.0-100.0 \mu \mathrm{M})$, DA (b, 5.0-750.0 $\mu \mathrm{M})$ and PY (c, 50.0-1000.0 $\mu \mathrm{M})$ in 0.1 M phosphate buffer ( $\mathrm{pH}$ 7.0). Inset shows the respective calibration plot. 
Limits of detection (LOD) calculated from $3 \mathrm{~S} / \mathrm{m}$ ratios (where $\mathrm{S}$ is the standard deviation of the blank and $\mathrm{m}$ is the slope of the calibration plot) are respectively $1.1 \mu \mathrm{M}$ for $\mathrm{AC}, 3.7 \mu \mathrm{M}$ for DA and $7.7 \mu \mathrm{M}$ for PY. This demonstrates the efficiency of SWCNTs in the quantification of all these species taken separately.

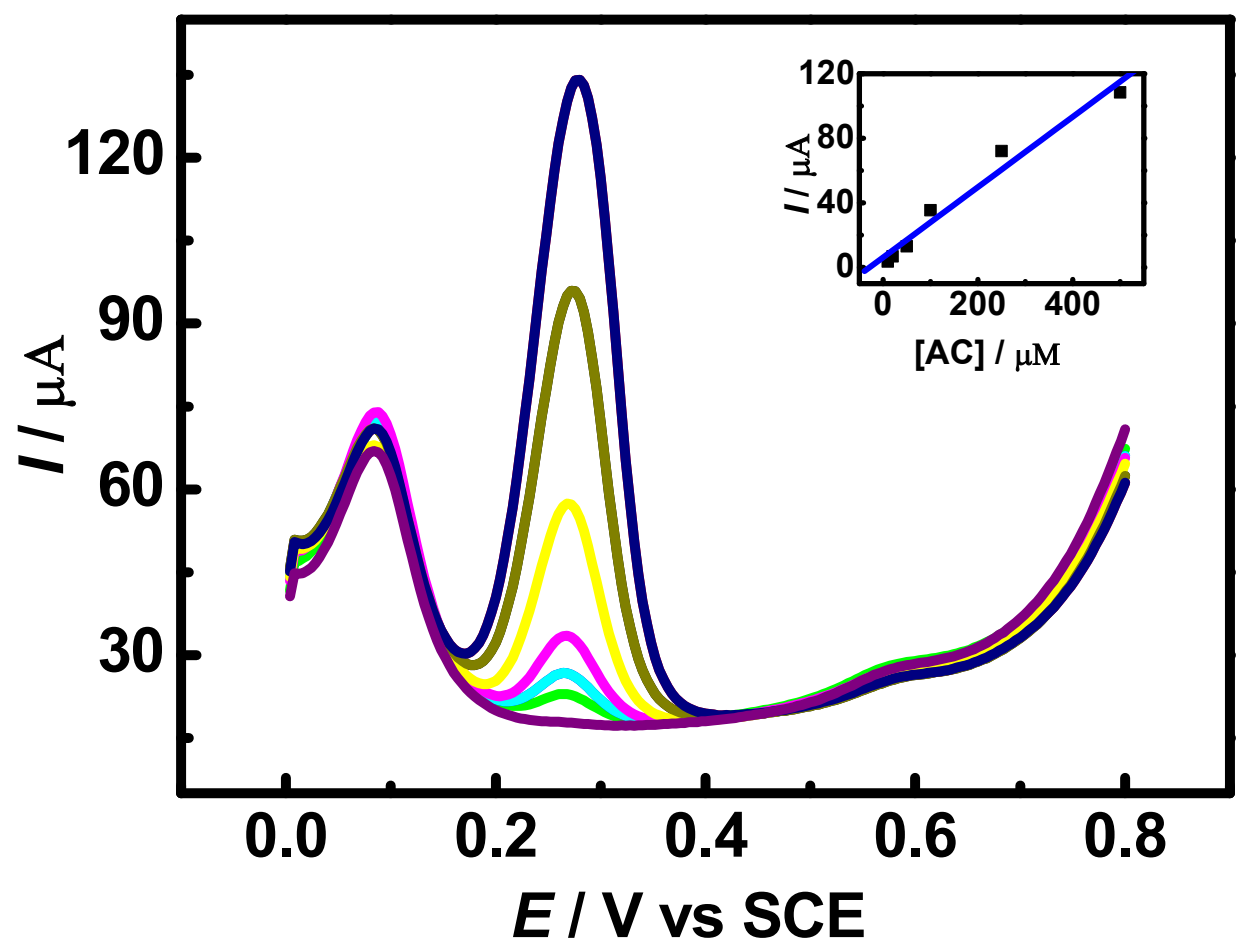

Fig. 6. DPV curves at GC/SWCNTs electrode for the determination different concentrations of $\mathrm{AC}(10.0-500.0 \mu \mathrm{M})$ in presence of DA $(0.1 \mathrm{mM})$ and PY $(0.1 \mathrm{mM})$ in $0.1 \mathrm{M}$ phosphate buffer $(\mathrm{pH} 7.0)$.

DPV is also employed for the quantification of AC in the presence of DA and PY (Fig. 6). The concentration of DA and PY is kept constant $(0.1 \mathrm{mM}$ each) and the concentration of AC is increased incrementally. As the concentration of $\mathrm{AC}$ is increased in the $10-500 \mu \mathrm{M}$ range, the DPV current response corresponding to its oxidation also increases regularly and no change in the current due to the oxidation of DA and PY is observed (Fig. 6). The inset in the Fig. 6 shows a linear calibration plot with an $r$ value of 0.98 . 
Table 1 Comparison of electroanalytical data for the present method along with previously reported methods for the electrochemical oxidation and determination of AC.

\begin{tabular}{|c|c|c|c|c|c|c|c|}
\hline Modified electrode $^{[\mathrm{c}]}$ & $\begin{array}{l}\text { Technique } \\
\text { used }\end{array}$ & Medium, pH & $\begin{array}{c}\text { Oxidation } \\
\text { Potential } \\
(\mathrm{V}) \\
\end{array}$ & $\begin{array}{c}\text { Linear range } \\
(\mu \mathrm{M})\end{array}$ & $\begin{array}{c}\text { Detection } \\
\text { limit } \\
(\mu \mathrm{M}) \\
\end{array}$ & Sensitivity & Reference \\
\hline Cu-poly-TTCA & $\mathrm{CV}$ & $\begin{array}{c}\text { Phosphate } \\
\text { buffer, pH } 7.0\end{array}$ & 0.48 & $20-5000$ & 5.00 & - & [13] \\
\hline GCE/Nafion/RuO & $\begin{array}{c}\text { SW } \\
\text { voltammetry }\end{array}$ & Perchloric acid & 0.70 & $5-250$ & 1.20 & - & {$[14]$} \\
\hline GCE/C60 & DPV & $\begin{array}{c}\text { Phosphate } \\
\text { buffer, pH } 7.2\end{array}$ & 0.50 & $50-1500$ & 50.00 & $\begin{array}{c}13.04 \mu \mathrm{A} \\
\mathrm{mM}^{-1}\end{array}$ & [15] \\
\hline $\begin{array}{l}\text { Multi walled carbon } \\
\text { nanotube/GCE }\end{array}$ & DPV & $\begin{array}{c}\text { Phosphate } \\
\text { buffer, pH } 7.38\end{array}$ & 0.34 & $5-100$ & 2.40 & - & {$[17]$} \\
\hline FeTPyPz/GCE & $\mathrm{CV}$ & $\begin{array}{l}\text { Acetate buffer, } \\
\text { pH 3.6. }\end{array}$ & 0.445 & $4-420$ & 1.20 & $\begin{array}{c}0.046 \mu \mathrm{A} \mu \mathrm{M}^{-} \\
{ }_{1} \mathrm{~cm}^{-2}\end{array}$ & {$[18]$} \\
\hline GCE/NiHCF-Bt & $\mathrm{CV}$ & $\begin{array}{c}\text { Phosphate } \\
\text { buffer, pH } 7.0\end{array}$ & 0.48 & $25-1000$ & 1.50 & $\begin{array}{c}0.20 \mu \mathrm{A} \mu \mathrm{M}^{-1} \\
\mathrm{~cm}^{-2}\end{array}$ & {$[46]$} \\
\hline
\end{tabular}




\subsection{Determination of AC: interference study, stability, reproducibility and real sample analysis}

The above data show that the GC/SWCNTs electrode looks promising for the sensitive and selective determination of $\mathrm{AC}$ and this is confirmed by Table 1 giving a comparison of the analytical parameters for the determination $\mathrm{AC}$ at the GC/SWCNTs together with other reported electrochemical methods $[12-17,46]$. As compared to the reported methods [12-17, 46], the present method shows low LOD, high sensitivity and low oxidation potential for the AC determination. Careful comparison of the parameters based on the data in Table 1 infers that the present method is superior over many other methods and therefore this route can be utilized for the selective quantitative recognition of AC even in the presence of DA and PY. The superior performance of the present electrode is mainly due to the different degree of interaction of SWCNTs, with the target analytes. Among the three analytes, AC interacts more with the SWCNTs probably due to the $-\mathrm{NHCOCH}_{3}$ group of $\mathrm{AC}[29,33,47]$.

In addition to DPV, the determination of the above analytes can be also performed by amperometry, as exemplified hereafter in the case of AC electroanalysis. Amperometry is an analytical technique in which a constant potential is applied to the working electrode and the resulting current is continuously monitored with addition of target analyte to the stirred supporting electrolyte at certain intervals of time. This approach is well suited to interference studies as it enables the alternative addition of either the analyte or the interference, for instance.

Selectivity of GC/SWCNTs on the determination of AC is evaluated by interference analysis. Supporting information, Figure S1 shows the amperometric determination of AC together with other potential interferent species. Accordingly in the present study, a potential of 0.25 
$\mathrm{V}$ is applied to the GC/SWCNTs electrode and after $300 \mathrm{~s}$, calculated amount of AC or possible interferents are injected to the supporting electrolyte $(0.1 \mathrm{M} \mathrm{pH} 7.0$ phosphate buffer). Whenever AC is injected, an immediate increase in current is observed (Supporting information, Figure S1) due to the oxidation of AC. Conversely, whenever the possibly interfering species, i.e., alanine, glycine, glucose, uric acid and tyrosine $(0.1 \mathrm{mM}$ each $)$ are injected, no change in the amperometric response is observed. Thus, the decreased AC oxidation potential avoids the interference from several oxidizable co-existing molecules, which can be useful in the determination of AC in real samples.

The reproducibility of the AC determination at the GC/SWCNTs electrode is tested by recording the DPV response (ten times at the interval of one minute, see Supporting information, Figure S2) of the oxidation of $0.1 \mathrm{mM} \mathrm{AC}$. The oxidation peak current for AC shows a relative standard deviation (RSD) of 3.8\%, signifying the high reproducibility of the determination. The stability (Supporting information, Figure S3) of GC/SWCNTs is established by keeping the electrode under room conditions and recording the CV response for $0.1 \mathrm{mM}$ AC determination on the $3^{\text {rd }}$ and $5^{\text {th }}$ days. The CV response retains $96.5 \%$ and $87.6 \%$ of the current respectively, as that of the initial response observed on the $1^{\text {st }}$ day indicating satisfactory storage stability.

To understand the practicability of the method for real sample analysis the response of GC/SWCNTs electrode towards the determination of AC present in a pharmaceutical tablet, DOLO (a product of Micro Labs Ltd., South Sikkim, India) is estimated. The tablet is carefully crushed into powder and solubilized in a mixture of water and ethanol (70:30). The DPV is recorded and the amount of AC is determined with the previously constructed calibration graph. In addition, the tablet solution is added with known amounts of standard 
$\mathrm{AC}$ and the recovery percentage is calculated. The results of the recovery analyses are shown in supporting information, Table S1. The average recovery was calculated to be $105.8 \%$ which is typical for such analysis. The RSD value for three measurements varies from 2.4 to $8.9 \%$ which indicate the acceptable reliability of this method.

\section{Conclusions}

This work demonstrates the electrochemical quantification of $\mathrm{AC}, \mathrm{DA}$ and $\mathrm{PY}$ using GC/SWCNTs modified electrode. It oxidizes AC, DA and PY at distinctly different potentials with decreased overpotentials due to the different degree of interaction with the SWCNTs. It also shows higher currents for the oxidation which is expected to increase the sensitivity in contrast to bare GC electrode. DFT calculations predict the order of interaction of the target analytes with the SWCNTs as AC $>$ PY $>$ DA which is in accordance with the electrochemical observations. This efficient electrocatalytic oxidation property of SWCNTs leads to the sensitive determination of AC, DA and PY. Interference studies demonstrate that this electrode is appropriate for the analysis of $\mathrm{AC}$ in samples of simple matrixes. The sensitivity $\left(7.9 \mu \mathrm{A} \mu \mathrm{M}^{-1} \mathrm{~cm}^{-2}\right)$, LOD $(1.1 \mu \mathrm{M})$ and linear calibration range $(2.0-100.0 \mu \mathrm{M})$

obtained in this study are superior to many other methods reported earlier for the determination of AC.

\section{Acknowledgements}

Generous financial support from DST-ASEAN (IMRC/AISTDF/R\&D/P-16/2018) program is gratefully acknowledged. We thank Prof. S. A. John, Gandhigram Rural Institute, India for useful suggestions. 


\section{References}

[1] Z. A. Alothman, N. Bukhari, S. M. Wabaidur, S. Haider, Sens. Actuators B 2010, 146, 314-320.

[2] W. Zhu, H. Huang, X. Gao, H. Ma, Mater Sci. Eng. C 2014, 45, 21-28.

[3] S. Tajik, M. A. Taher, H. Beitollahi, Sens. Actuators B 2014, 197, 228-236.

[4] A. Cernat, M. Tertis, R. Sandulescu, F. Bedioui, A. Cristea, C. Cristea, Anal. Chim. Acta 2015, 886, 16-28.

[5] H. Bagheri, A. Afkhami, P. Hashemi, M. Ghanei, RSC Adv. 2015, 5, 21659.

[6] J. Yang, D. Mu, Y. Gao, J. Tan, A. Lu, D. Ma, J. Nat. Gas Chem. 2012, 21, 265-269.

[7] O. Gilbert, B. E. K. Swamy, U. Chandra, B. S. Sherigara, Int. J. Electrochem. Sci. 2009, 4, 582-591.

[8] M. A. Raj, N. S. K. Gowthaman, S. A. John, J. Colloid Interface Sci. 2016, 474, 171 178.

[9] M. H. Pournaghi-Azar, H. Dastangoo, M. Ziaei, J. Solid State Electrochem. 2007, 11, $1221-1227$

[10] S. Q. Liu, M. L. Cao, S. L. Dong, Bioelectrochemistry 2008, 74, 164-169.

[11] B. Habibi, H. Phezhhan, M. H. Pournaghi-Azar, J. Iran. Chem. Soc. 2010, 7, S103S112.

[12] P. B. Desai, R. M. Kotkar, A. K. Srivastava, J. Solid State Electrochem. 2008, 12, 1067-1075.

[13] M. Boopathi, M. S. Won, Y. B. Shima, Anal. Chim. Acta 2004, 512, 191-197.

[14] J. M. Zen, Y. S. Ting, Anal. Chim. Acta 1997, 342, 175-180.

[15] R. N. Goyal, S. P. Singh, Electrochim. Acta 2006, 51, 3008-3012.

[16] S. A. Kumar, C. F. Tang, S. M. Chen, Talanta 2008, 76, 997-1005. 
[17] Q. Wan, X. Wang, F. Yu, X. Wang, N. Yang, J. Appl. Electrochem. 2009, 39, 11451151.

[18] M. D. P. T. Sotomayor, A. Sigoli, M. R. V. Lanza, A. A. Tanaka, L. T. Kubota, J. Braz. Chem. Soc. 2008, 19, 734-743.

[19] R. A. Durst, A. J. Baumner, R. W. Murray, R. P. Buck, C. P. Andrieux, Pure \& Appl. Chem. 1997, 69, 1317-1323.

[20] H. Teymouriana, A. Salimia, R. Hallaj, Talanta 2012, 90, 91-98.

[21] J. Wang, M. Musameh, Anal. Chem. 2003, 75, 2075-2079.

[22] P. K. Sonkar, V. Ganesan, D. K. Yadav, R. Gupta, ChemistrySelect 2016, 1, 67266734.

[23] P. K. Sonkar, K. Prakash, M. Yadav, V. Ganesan, M. Sankar, R. Gupta, D. K. Yadav, J. Mater. Chem. A 2017, 5, 6263.

[24] P. K. Sonkar, V. Ganesan, S. A. John, D. K. Yadav, R. Gupta, RSC Adv. 2016, 6, 107094.

[25] J. J. Gooding, Electrochim. Acta 2005, 50, 3049-3060.

[26] A. Walcarius, S. D. Minteer, J. Wang, Y. Lin, A. Merkoçi, J. Mater. Chem. B 2013, , $1,4878-4908$.

[27] C. Yang, M. E. Denno, P. Pyakurel, B. J. Venton, Anal. Chim. Acta 2015, 887, 17-37.

[28] A.C. Power, B. Gorey, S. Chandra, J. Chapman, Nanotechnol. Rev. 2018, 7, 19-41.

[29] H. Luo, Z. Shi, N. Li, Z. Gu, Q. Zhuang, Anal. Chem. 2001, 73, 915-920.

[30] X.-Q. Lin, J.-B. He, Z.-G. Zha, Sens. Actuators B 2006, 119, 608-614.

[31] N. Saifuddin, A. Z. Raziah, A. R. Junizah , J. Chem. 2012, Doi: 10.1155/2013/676815.

[32] W. Zhang, Q. Ding, J. JinRuan, J. Fang, B. H. Ruan, Austin. Biomol. 2016, 1, 1005.

[33] J. Wang, Electroanalysis 2005, 17, 7.

[34] C. E. Banks, R. G. Compton, Analyst 2006, 131, 15-21. 
[35] S. Alwarappan, G. Liu, C.-Z. Li, Nanomedicine 2010, 6, 52-57.

[36] Y. Li, J. Du, J. Yang, D. Liu, X. Lu, Colloids Surf. B 2012, 97, 32-36.

[37] R. N. Goyal, V. K. Gupta, S. Chatterjee, Sens. Actuators B 2010, 149, 252-258.

[38] F. Valentini, S. Orlanducci, E. Tamburri, M. L. Terranova, A. Curulli, G. Palleschi, Electroanalysis 2005, 17, 28-37.

[39] D. Xiao, W. Sun, H. Dai, Y. Zhang, X. Qin, L. Li, Z. Wei, X. Chen, J. Phys. Chem. C 2014, 118, 20694-20701.

[40] M. Ghalkhani, J. Beheshtian, M. Salehi, Mater. Sci. Eng. 2016, 69, 1345-1353.

[41] R. Savalia, S. Chatterjee, Sens. Actuators B 2018, 277, 39-46.

[42] M. J. Frisch, G. W. Trucks et.al. H.B.S. GAUSSIAN 09, Gaussian, Inc., Wallingford CT 2010, Revision C.01.

[43] W. Y. Su, S. H. Cheng, Electroanalysis 2010, 22, 707-714.

[44] E. Colín-Orozco, S. Corona-Avendaño, M. T. Ramírez-Silva, M. Romero-Romo, M. Palomar-Pardavé, Int. J. Electrochem. Sci. 2012, 7, 6097-6105.

[45] C. A. Fonseca, G. C. S. Vaz, J. P. A. Azevedo, F. S. Semaan, Microchem. J. 2011, 99, $186-192$.

[46] M. Yadav, P. Singh, V. Ganesan, R. Gupta, P. K. Sonkar, D. K. Yadav, Electroanalysis 2018, submitted.

[47] Q. Zhao, Z. Gan, Q. Zhuang, Electroanalysis 2002, 14, 23. 